\title{
Forest Fire Induced Natech Risk Assessment: A Survey of Geospatial Technologies
}

\author{
Mohsen Naderpour ${ }^{1,2}$, Hossein Mojaddadi Rizeei ${ }^{2}$, Nima Khakzad ${ }^{3}$, Biswajeet Pradhan ${ }^{2, *}$ \\ ${ }^{1}$ Centre for Artificial Intelligence, Faculty of Engineering and IT, University of Technology Sydney, \\ Ultimo, NSW 2007, Australia \\ ${ }^{2}$ Centre for Advanced Modelling and Geospatial Information Systems (CAMGIS), Faculty of \\ Engineering and IT, University of Technology Sydney, Ultimo, NSW 2007, Australia \\ ${ }^{3}$ Faculty of Technology, Policy, and Management, Delft University of Technology, Delft, The \\ Netherlands
}

\begin{abstract}
Forest fires threaten a large part of the world's forests, communities, and industrial plants, triggering technological accidents (Natechs). Forest fire modelling with respect to contributing spatial parameters is one of the well-known ways not only to predict the fire occurrence in forests, but also to assess the risk of forest-fire-induced Natechs. This study is a review of methods based on geospatial information system (GIS) for modelling forest fires and their potential Natechs that have been implemented all over the world. The present study conducts a systematic literature review of the methods used for forest fire susceptibility, hazard, and risk assessment, while dividing them into four general categories: a) statistical and data-driven models; b) machine learning models; c) multi-criteria decision-making models, and d) ensemble models. In addition, some forest fire detection techniques using satellite imagery are reviewed. A comparison is also conducted to highlight the research gaps and required future research. The results of the present research assist decision makers to select the most appropriate techniques according to specific forest conditions. Results show that data-driven approaches are the most frequently applied methods while ensemble approaches are more accurate.
\end{abstract}

Key Words: Forest fire, Industrial plants, Natech, Risk, Geospatial information system.

\section{Introduction}

Forest fires resulting from natural or human causes have harmful and destructive effects directly or indirectly on human societies. They have a huge impact on the environment and inhabitants due to the ever-increasing concentration of the population and industrial areas in wildlands [1-3]. Although forest fires are an inseparable part of these ecosystems, their noncompliance can cause significant economic and environmental damage [4]. Nowadays, the forest fire phenomenon influences a large part of the world's forests, endangering rare

\footnotetext{
* Corresponding author

Email addresses: Mohsen.Naderpour@uts.edu.au, Hossein.MojaddadiRizeei@uts.edu.au, N.KhakzadRostami@tudelft.nl, Biswajeet.Pradhan@uts.edu.au
} 
species and destroying thousands of hectares of trees, shrubs and herbivores [5-7]. The average perennial damage of forest fire in the world is estimated to be around six to fourteen million hectares [8]. Forest fires can result in worst-case scenarios by triggering industrial accidents that are nowadays referred to as "Natechs" and are considered an emerging risk due to ongoing climate change and growing industrialization [9]. Due to the increasing frequency of forest fire, it is necessary to design and develop effective methods of coping [10, 11]. To reduce the damage caused by forest fires, fire control managers require an assessment of fire susceptibility, hazard, and risk [12].

Forest fire susceptibility is the probability of wildfire occurrence based on certain thresholds [13]. Forest fire hazard refers to potential fire behaviour such as fire-line intensity or the chemical and physical properties of forest fuel such as forest biomass [14]. Accordingly, the risk of forest-fire-induced damage to humans, assets, and the environment can be defined based on the fire likelihood, fire behaviour, and the impact of fire on the target [15]. Forest fire vulnerability defines the location of inhabitants, properties, housing, infrastructures, and other physical human resources located in forest fire susceptible areas [16]. Forest fire vulnerability illustrates the probable loss from forest fires. The spatial approximation of forest fire hazard and risk can be challenging, depending on the complexity of forest fire through various spatiotemporal scales [17].

When a forest fire occurs, it is difficult to analyse the behaviour of the fire due to the difficulty of collecting the required simulation parameters. By using models, maps, and databases in geospatial information system (GIS), it is possible to simulate the fire and collect and analyse information from forests which have the highest risk of fire occurrence [18]. Using these methods, the risk of forest fire and potential Natechs can be reduced, for instance, by allocating watchtowers and watchdogs in risky areas, and risk-based land use planning [19]. It is also possible to combine information on the fire hazard level and forest accessibility in relation to the distribution of facilities in high-risk areas [20]. On the other hand, satellite imagery and remote sensing (RS) analysis can be widely used to detect and monitor the behaviour of fire for operational activities [21]. These technologies are not only more efficient and precise than traditional surveying methods, they also save in terms of time and human lives [22].

In this study, a systematic literature review is conducted on the current methods used in forest fire and related Natech domains using geospatial technologies such as GIS and RS. The paper categories the methods, discusses their advantages and disadvantages, and provides more insights for future research in this area.

The rest of the paper is organized as follows: Section 2 presents the background on forest fires while Section 3 details the research methodology. Section 4 shows the results followed by a discussion on the research challenges and future directions in Section 5. Section 6 concludes the paper.

\section{Background}

Forest fire is one of the main threats to the environment with negative impacts which sometimes last more than 10 years after the event. It has also an increasing trend that requires a precise and effective control strategy [23]. In 2017, forest fires burnt over 1.2 million ha of 
natural lands in the EU and killed 127 people, both fire fighters and civilians. Over $25 \%$ of the total burnt area was in the Natura 2000 network, destroying much of the efforts of EU countries to preserve key biodiversity and natural habitats for future generations. According to the European Forest Fire Information System, the losses caused by these fires are estimated to be around 10 billion euros [24].

Forest fire investigation approaches can be divided into two categories: fire direction and fire prediction modelling approaches $[12,25]$. Considering the importance of forest fire hazards, various studies have been carried out worldwide [26]. The Canadian Forestry Service has conducted forest fire research for more than 75 years [27], and the first application of RS to forest fire detection dates back to the 1960s, when several infrared aerial scanners were used to track fire points and to assess the risk of forest fires [28-31]. In the present study, we focus more on fire prediction and detection models for forest fire susceptibility, hazard and risk analysis and Natech risk assessment.

Forest fire is usually considered an unrestrained phenomenon that wipes out vast areas of bushland and forests. It can be triggered by lightning strike or human-made ignitions that go unnoticed [32]. These fires sometimes burn for days and weeks especially in warm and dry weather. They are able to wipe out whole forests and destroy every organic thing in its path.

Forest fire also has a significant impact on the destruction of fauna and flora and forest landscape, and its effects are felt at every level of the ecosystem [3, 34]. In addition, based on their severity and repetition, forest fires can cause changes to species qualities and leads to the establishment of unsustainable species that may not be economically valuable.

According to existing research, the spatial factors contributing to forest fire are climate and weather (e.g. wind speed, wind direction, rainfall, humidity, temperature, solar radiation and seasonal variations), the morphological factors are slope, aspect, curvature, topographical indices, altitude, distance from river, distance from man-made properties, soil moisture and texture and the fire fuel parameters are tree condition and material, types of wood, type of land cover and forest density [8, 35-38].

Although forest fires are an integral part of ecosystems, uncontrolled fires may cause severe economic and environmental damage [33,34]. With the extension of wildlandindustrial interfaces (mainly due to population growth and industrialization), the economic damage of forest fires especially in terms of damage to industrial facilities and infrastructures has drawn much recent attention. In May 2016, forest fires burned part of Fort McMurray, Alberta, Canada, and moved towards the oil sands operation facilities north of the city. Although the fire did not reach the oil sands facilities (due to a fortuitous shift in the wind direction), it resulted in a $40 \%$ drop in oil production due to the shutdown of the oil sands facilities nearby, resulting in a loss of $\$ 760$ million [35].

Despite the emerging risk of forest-fire-induced Natechs, there have been relatively few risk assessment and management studies [36-40], especially due to the complexity and high uncertainty associated with the prediction and modelling of forest fires from one side and the assessment of the impact of forest fires on industrial facilities from the other side. Heymes et al. (2013) conducted numerical simulations of storage tanks exposed to wildfire to demonstrate that in most cases the safe distance between fuel storage tanks in wildlandresidential interfaces is not large enough to sufficiently lower the amount of heat radiation 
that storage tanks may need to withstand from potential forest fires. Recently, Khakzad (2019) developed a methodology based on dynamic Bayesian networks and fire behaviour simulation models to predict and model fire spread in wildland-industrial interfaces. Considering forest fire as a solid flame, they showed that forest fire could trigger a domino effect in process facilities if insufficient buffer zones expose the process units to the intense heat radiation of a forest fire.

\section{Research Methodology}

The research methodology is based on the PRISMA statement which explains the preferred reporting items for systematic reviews and meta-analyses [41, 42]. The research methodology is illustrated in Figure 1 and is elaborated in the following.

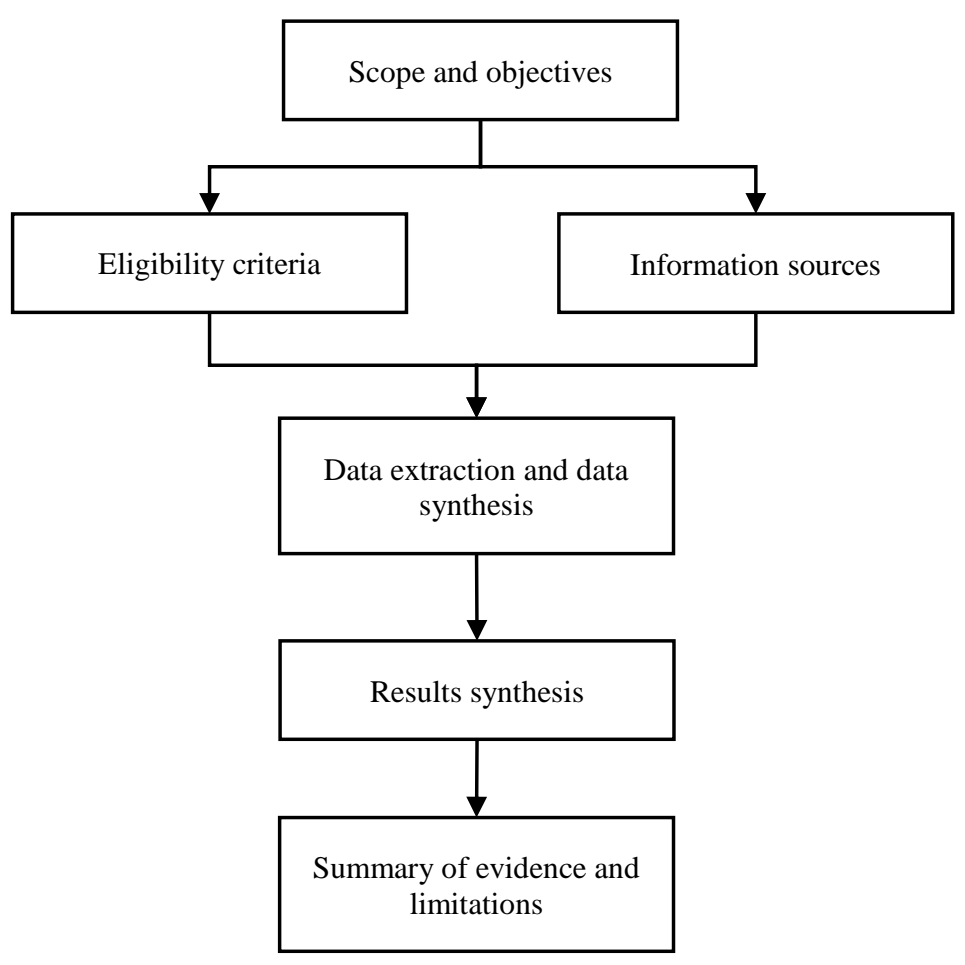

Fig 1: Research methodology

- Scope and objectives: As described in the introduction, the scope of the review is forestfire-induced Natech risk assessment and the objective is to review the state-of-the-art methods developed over the last decade.

- Eligibility criteria: A set of inclusion and exclusion criteria to identify studies contributing to the objective is determined. The inclusion criteria are as follows:

- Published in peer-reviewed journals or conferences

- Written in English

- Published between 2000 and 2018

- Developed a risk assessment method using geospatial technologies

The exclusion criteria are as follows: 
- Studies not using geospatial technologies

- Full-texts are not available from publishers

- Information sources: Scopus and Web of Science.

- Data extraction and data synthesis: To extract the relevant research, several combinations of keywords are proposed: 1) forest fire, risk assessment, geospatial analysis; 2) forest fire, hazard assessment, GIS; 3) forest fire, susceptibility assessment, GIS; 4) forest fire, detection, remote sensing satellite imageries. The data extraction process is presented in Figure 2. As can be seen, 64 records were initially identified. After removing the duplicated papers, 58 inputs were fed into the next step. To check eligibility, the titles, keywords, and abstracts were evaluated by the authors.

- Results synthesis: The obtained papers were categorized based on the objective. Section 4 presents the results in more detail.

- Summary of evidence and limitations: The main findings are discussed in Section 5, including the strength of evidence for each main outcome, the limitations of the current studies, and recommendations for future studies.

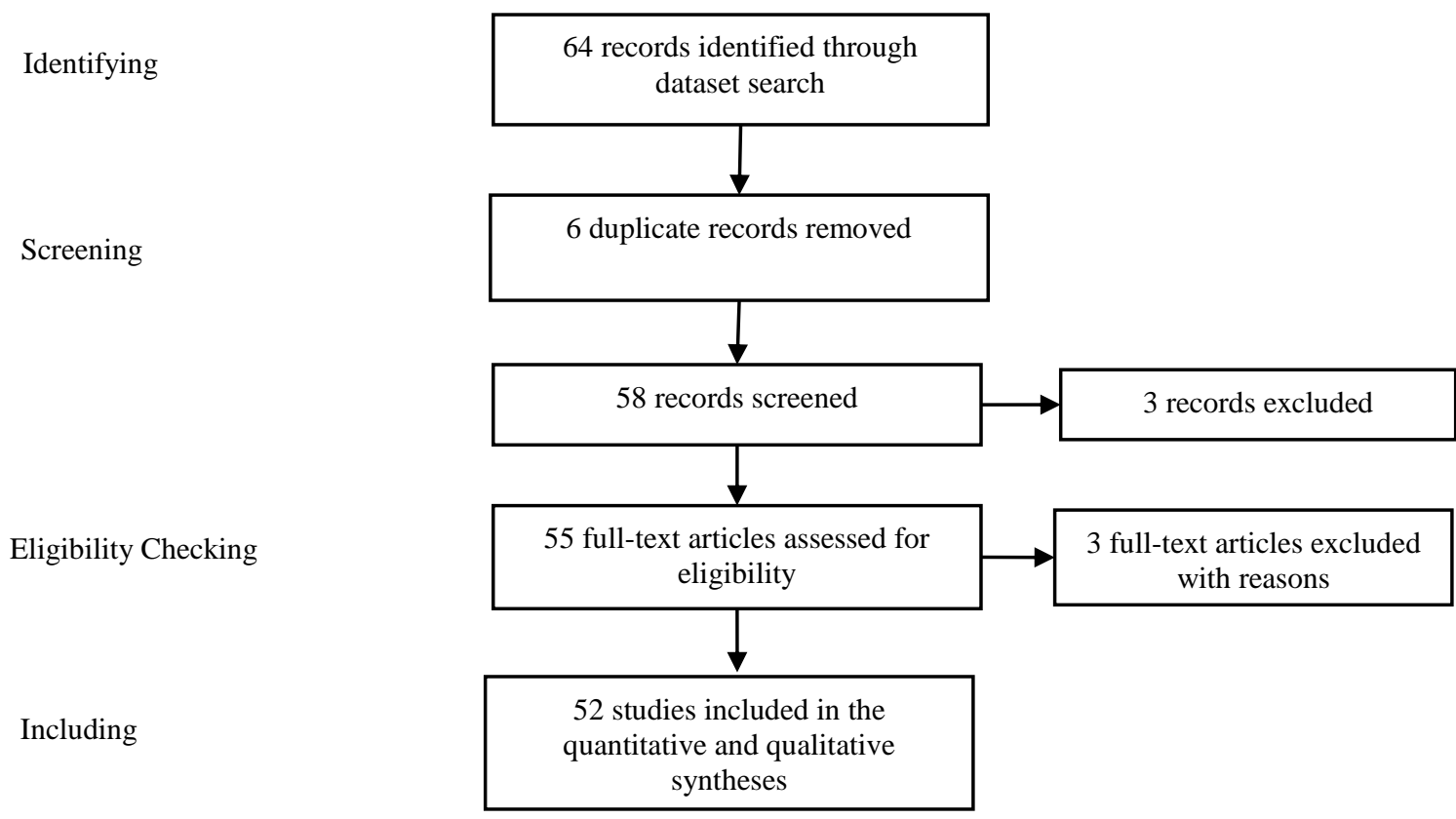

Fig 2: Data extraction process

\section{Results}

Different forest fire and related Natech risk assessment models that use geospatial technologies were categorized and compared. Figure 3 shows the overall computational framework that covers the methodologies of the reviewed papers. 


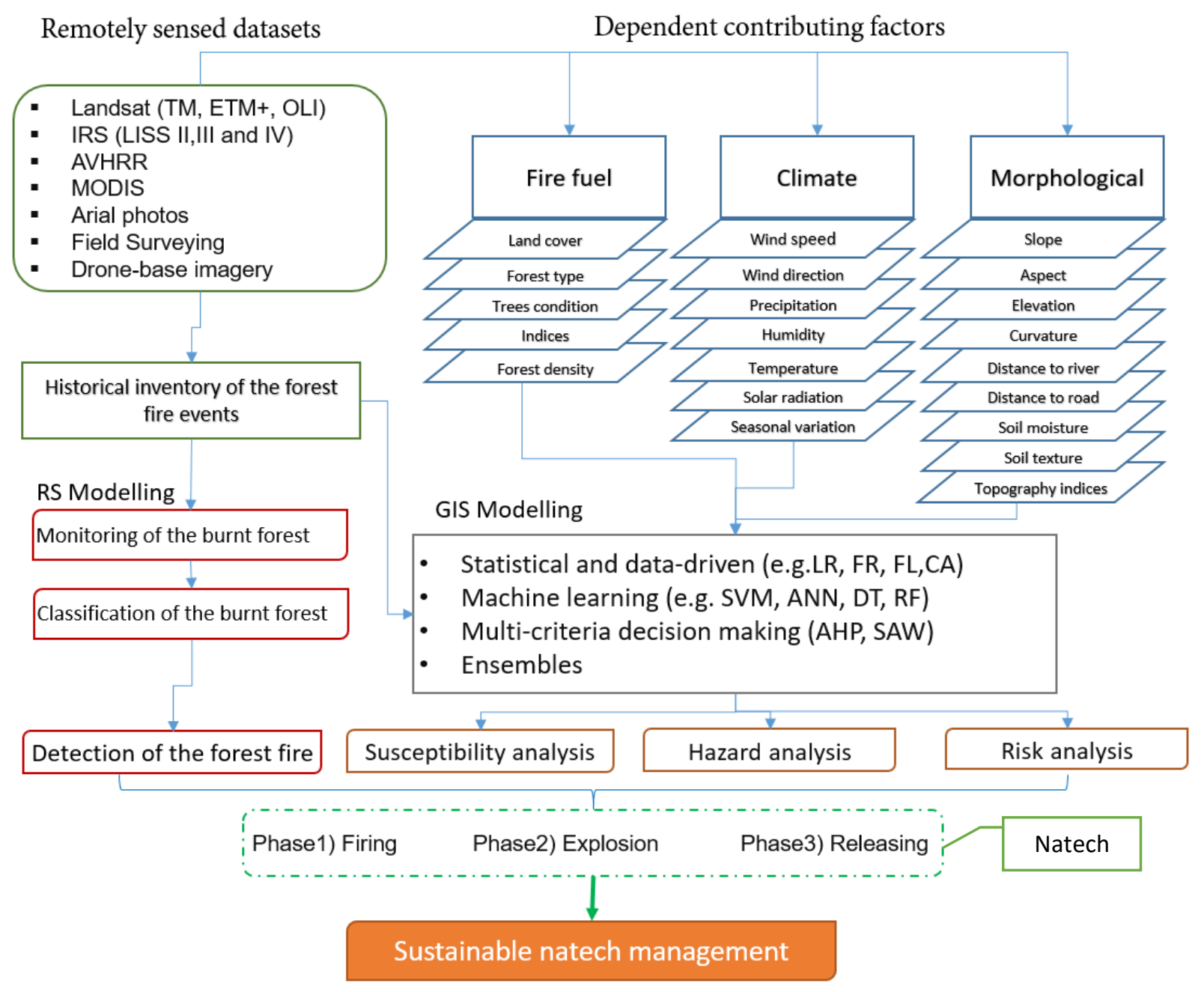

Fig 3. Methodology of forest fire modelling using geospatial technologies

The obtained models are categorized into statistical and data mining methods, machine learning (ML), multi-criteria decision making (MCDM), and ensemble methods. In addition, a review of fire detection methods using RS is conducted. The applied methods are compared according to the dataset, contributing factors, accuracy and results to highlight the pros and cons of each method.

\subsection{GIS-based forest fire susceptibility, hazard and risk mapping}

The latest advances in forest fire modelling have led to several new methodologies for implementing susceptibility, hazard and risk assessment frameworks which allow decision makers and firefighters to evaluate forest fire risk models more effectively. Nowadays, computer models are able both to conduct spatially explicit forest fire simulations over dissimilar forest fuels and to map fire characteristics on a large scale.

\subsubsection{Application of statistical and data-mining models}

In the research conducted by Rollins, Keane et al. [43], a hybrid approach was developed to produce predictive maps of forest fires in Northwest Montana, USA using broad-scale landbased sampling, RS, ecosystem simulation and biophysical slope modelling. Different maps 
were prepared using linear models, logistic regression (LR) and decision trees (DTs). The results showed that the method used under different climate scenarios can be updated based on potential future conditions and the accuracy of these maps ranged from $51 \%$ to $80 \%$.

Pradhan and Awang [44] investigated forest areas susceptible to forest fire in Malaysia's Kuala Selangor region using the likelihood ratio method in GISs. To do this, NOAA satellite AVHRR sensor data from 2000 to 2005 was used. The vegetation maps and the normalized difference vegetation index (NDVI) were derived from the Landsat 7 satellite ETM. Other factors such as slope, aspect and altitude were calculated using a topographic map. Forest fire contaminated areas were classified using maximum effective factors. Then, these areas were shown to be accurate using past fire location data. The results also show that the frequency ratio model had a very high prediction accuracy for forest fire susceptibility mapping.

Lozano, Suárez-Seoane et al. [45] modelled the relationship between the probability of occurrence of fire and various environmental factors on different scales using regression models relying on satellite imagery and developed a model to show the probability of the occurrence of fire based on topographic characteristics, accessibility, type of vegetation coverage and fire history in the Mediterranean. The random sampling method was used and the effective factors were divided into variables and constant parameters. The results based on tree regression models show the occurrence of fire with environmental factors is very different in dissimilar spatial scales. In most cases, fire hazard areas are located in the bootstrap and on steep slopes. In addition, fire locations are associated with past fire events.

In another study, Martínez, Vega-Garcia and Chuvieco [46] investigated the human factors associated with the risk of fire in Spanish forests and analysed the distribution of fire in the country over the past 13 years. To do this, 108 human-made fire events were generated and input to a dedicated GIS to model various factors associated with the occurrence of the fire. After the initial analysis, 29 variables were selected to construct a prediction model of human fire ignition using logistic regression analysis and an ignition danger index was developed. Thirteen explanatory variables were identified by the model associated with fragmentation of agricultural areas, agricultural abandonment and development processes. These variables include road density, railway line density, rural population, agricultural machinery density, density of agricultural plots, livestock density, forest density and density of the interface between risk infrastructures (waste dumps, mines, quarries etc) and forest areas. Due to population growth, there was an increase in owners of agrarian holdings between 1989 and 1999. The correlation between the output of the predictive model and the fire history data was $85.3 \%$. Therefore, the constructed model can be used as a good predictor of human fire hazards to enhance spatial decision-making in relation to fire prevention programs.

Perera and Cui [47] modelled and predicted fire regime characteristics in Ontario, Canada and mapped the probability of fire based on slope, direction, vegetation, soil moisture and other factors in five classes. They used a dynamics simulator to examine the long-term fire regime in relation to forest policies on harvest size distribution. The fire behaviour in four large eco-regions was modelled for a 200-year period under three fire-weather scenarios (i.e. warm, normal, and cold), with replications. The results showed a high correlation between the fire simulation model and past fire events. In addition, predicting future forest fires can help forest managers to manage future fire occurrences. 
Keane, Drury et al. [48] also presented a program for forest fire crisis management using RS and GIS in the Canadian border region in northern Montana. This study presents a method for mapping fire risk and fire hazard using a model called FIREHARM (FIRE Hazard and Risk Model), which calculates mutual measures of fire behaviours using a regression algorithm. For this reason, a map of the fire contributing factors for hazard zonation was prepared using RS and the area was divided into several operating units for the sustainable management in case of forest fire. The results showed that combining fire risk zoning maps with operational classes is a useful strategy for fire management, and RS and GIS are highly effective in this regard.

Cuvieco, Aguado et al. [49] presented a framework for assessing the risk of fire and the provision of fire hazard indicators using GIS and RS. In this study, methods to generate the input variables and their combination for fire hazard mapping in several regions of Spain were developed. After designing the conceptual model to assessing fire risk, conditioning variables including human factors, lightning, fuel map, vegetation type, live and dead fuel moisture, soil maps, digital elevation model, land use, recreational areas, regions protected, meteorological data, and population density data, were assessed to find the optimal threshold in spatial information and RS systems. This system was tested by the end-user in 2007. In this research, a validation assessment of the fire risk index was presented by comparing the components of fire risk and fire in different regions.

Zumbrunnen, Pezzatti et al. [50] examined the impact of climate and human factors on forest fires in two susceptible areas in Switzerland over a 100-year period using a GIS-based correlation model. The results showed that the climate and the existence of roads and livestock played an important role in the occurrence of fire in two areas. In addition, there was a nonlinear relationship between fire and human factors. In warmer climates, the probability of fire occurrence is much higher regardless of human activities.

Jurdao, Chuvieco et al. [51] modelled the probability of forest fire from satellites by estimating the amount of moisture in the Mediterranean region. The purpose of this study was to evaluate the different methods of estimating the amount of air moisture of burning forest to the probability of a fire at the national level regarding the climate and types of vegetation. The data on the moisture content of live fuel extracted from the AVHRR sensor and the MODIS fire detector was used to detect forest fire events. Nonparametric statistical tests, a classification tree and a logistic regression model were used to estimate the probability of fire occurrence based on the amount of moisture content of living fuel. Finally, LR was selected to calculate the probability of a fire due to a high number of predictive variables. The results showed that the amount of forest moisture content one week before a fire occurrence was the most important variable in statistical analysis and the most important variable for predicting a potential fire occurrence in the Mediterranean region.

Román, Azqueta et al. [52] presented a method for assessing the socio-economic vulnerability of Spanish forests to fire using a GIS. The vulnerability was assessed by estimating the potential losses fire might cause during the time required for the recovery of the pre-fire environmental conditions. With regard to the socio-economic issues at risk, three categories of impact were assessed, these being the impact on human beings, the impact on properties such as the destruction of structures and the impact of the loss of environmental 
services due to the affected ecosystems. The results showed that the average benefits derived from effective fire prevention measures in relation to the impact on property, human life and ecosystems are 376585, 9.17 and 22.29 euros per square kilometre.

Gerdzheva [53] presented a comparative analysis of different models of fire risk assessment in the Smolyan region of Bulgaria. The purpose of this study was to determine an appropriate risk assessment model for this area. All the contributing factors were reclassified and weighted according to their contribution to forest fire and were calculated by linear regression with fire inventory events. Accordingly, three fire hazard zones were selected. The results of each model were compared with the history of previous fire events.

Eskandari and Chuvieco [54] assessed the risk of fire in Iran's vegetation cover (forests and pastures). The forest fire assessment in this study was divided in two parts, the risk of fire occurrence and the probability of fire spreading, using the LR model and Flam-map, respectively. To evaluate the models, the MODIS fire detector was used over a 12-year period (2002 - 2013) with information on past fire events. The results showed that the logistic regression model achieved $72.7 \%$ accuracy in predicting the probability of the occurrence of fire in Iran's forests.

Chuvieco, Aguado et al. [55] assessed the risk of a fire in Spanish forests using correlation analysis. The paper describes the conceptual model framework and then the input variables were generated and approaches to merge these variables into synthetic risk indices, and finally, the validation of the model was discussed. The fire risk factors, which included human variables, thunderstorms, dead leaves, vegetation type, were assessed accordingly. Incidence and spread indicators were validated using the latest available fire inventory. The results showed significant relationships between the occurrence of fire and the amount of wood moisture.

Eskandari and Chuvieco [54] investigated the relationship between climate and fire in the forests of Golestan province in Iran using a linear regression model. The results of this research showed that there was a significant relationship between the number of fires and the average annual temperature at a 95\% confidence level. There was also a significant relationship between the number of fires and average annual relative humidity at a $99 \%$ confidence level, while there was an insignificant relationship between the number of fires and the average annual rainfall.

You, Lin et al. [22] established a conceptual frame for fire risk mapping, integrating the Forest Resource Inventory Database (FRID) in sites where there is a shortage of fire-related research data. They also quantified the potential forest fire risk and map risk zones, and examined the spatio-temporal variation of forest fire risk. The study area was located in the northwest of the Fujian province of China. They used a spatial statistics technique named exploratory spatial data analysis (ESDA) and semi-variance analysis. Different forest types, including lanceolate forests, broadleaf forests, bamboo forests, shrub and grass, economic forests, P. massoniana forests and tea plantations were analysed to generate a fire risk map. The input data that was used in their method are DEM, forest resource inventory, LULC map, meteorological data as well as aspects of topographical, human activity, climate, and forest characteristics factors. They generated a forest fire risk index map and a map of forest fire risk zones from 1997 to 2009. 
Jaafari, Gholami et al. [81] modelled wildfire probability in the Zagros forest in south western Iran. Weights-of-evidence (WOE) Bayesian modelling was used to investigate the spatial relationship between historical fire events in the forests of the Zagros Mountains. Forest fire inventory field surveying data including topography, climate, and human activity measures were used. The forests are dominated by Persian oak with small amounts of Common pistachio, Montpellier Maple, Wild Pear, Hawthorn, Almond, Ash, Myrtle, Juniper, Oriental plane, and Honeysuckle. The validation results confirmed the very good predictive ability of the model which had AUC values of 84.2 and $80.4 \%$ for success and prediction rates, respectively. The main advantage of the WOE model in wildfire probability analysis is its ability to incorporate multiple sources of information. The results from this study may be useful for land use planning, decision-making for wildfire management, and the allocation of fire resources prior to the start of the main fire season.

Hong, Naghibi et al. [56] compared the performance of four models, namely frequency ratio (FR), weights-of-evidence (WoE), and linear and quadratic discriminant analysis (LDA and QDA) to model forest fire susceptibility in the Yihuang area in China. They used MODIS satellite images, field survey data and topographic maps on a scale of 1:50,000 with 25-meter resolution. To do this, the following thirteen forest fire conditioning parameters were chosen: slope degree, slope aspect, altitude, topographic wetness index (TWI), plan curvature, land use, NDVI, annual rainfall, distance from roads, distance from rivers, wind effect, annual temperature, and soil texture. The results indicated that WoE had the best performance (AUC $=82.2 \%)$, followed by FR (AUC $=80.9 \%)$, QDA $(\mathrm{AUC}=78.3 \%)$, and $\mathrm{LDA}(\mathrm{AUC}=78 \%)$, respectively. The produced fire susceptibility maps can help natural hazard managers in determining high potential fire danger areas. These models could be implemented in other areas confronting the forest fire problem by altering the effective factors and the weights.

\subsubsection{Application of ML models}

The research conducted by Vadrevu, Eaturu et al. [57] investigated the risk of forest fires in Andhra Pradesh, India using a multivariable analysis in a fuzzy inference system (FIS) method using satellite data with socio-economic, climatic, vegetation data and topography. All the data were organized at the regional level in the GIS. The results showed that the weight of socioeconomic, climatic, vegetation and topographic factors was $0.322,0.223,0.255$ and 0.204 , respectively. The results of the fire risk map with the pixels of fire from the satellite images were overlapped. Because of the consistency of hazardous fire areas up to $64.4 \%$, the reliability of the model was built to identify the critical areas for which the risk of fire was relatively high. The results of this study showed that the multi-criteria decision-making capability with GIS is very effective and can act as a valuable tool in predicting where and when fire will occur.

Sakr, Elhajj et al. [58] studied forest fire prediction methods based on artificial intelligence. They developed two forest fire risk prediction algorithms based on SVM and an artificial neural network (ANN) to predict forest fire hazard in relation to the previous climatic conditions. The results showed that with a limited number of parameters, the SVM and ANN have high accuracy to predict potential areas that are threatened by fire. 
Sitanggang, Yaakob et al. [59] presented a predictive model for detecting fire hotspots using DT-C 4.5 and DT-ID-3 algorithms in the context of Indonesian forests. The data used included 10 functional layers (physical, climatic, and socioeconomic) and a fire inventory map. The results showed that the DT-C-4.5 tree algorithm was better rather than DT-ID3 with a precision of $65.24 \%$. In addition, the logistic regression model achieved higher accuracy than the decision tree algorithm with a precision of $63.68 \%$.

\subsubsection{Application of MCDM models}

Chuvieco and Congalton [28] prepared a map of areas at critical risk of fire on the Spanish coast of the Mediterranean using the processed Landsat TM satellite image and other ancillary data using a GIS. The factors used included vegetation type, mass conditions, slope, aspect, and elevation, proximity to roads, residential areas and camping sites. The layers were integrated using the AHP model. The areas susceptible to forest fire were compared with the forestlands which had burned previously. The results showed that $22 \%$ of the pixels that were burned previously fell in high-risk areas which were burned in recent years, while only 3.47 $\%$ of the forest low-risk areas had been burned in past events.

Almeida [60] produced a map of areas of Portuguese forests which are at risk of fire based on forest species factors, slope, geographic location, distance from roads and permanent rivers. The variables were categorized based on the fire hazard coefficient in the GIS. Five risk classes were obtained for the region. Hazard areas were those which had a slope of more than 40 percent, an aspect range from 135 to 225 degrees (west), located more than 30 meters from rivers, and covered by trees and bushes.

Akpinar and Usul [61] produced a map of forest fire susceptibility in the context of Turkey using RS and GIS and examined the adequacy of firewall towers in the region using GIS. Desirable functions for forest fire analysis were selected using decision support techniques and the fire hazard map was developed. Then the map of hazard zones was merged with the visibility of the observation towers to determine the high-risk areas, where existing towers have visual coverage. The results showed that most of the high-risk areas are accessible by existing towers. However, for moderate observing areas in the north of the region, an additional observation tower is needed. In addition, GIS is highly effective in terms of information management and the prediction of forest fire.

Jaiswal, Mukherjee et al. [62] used satellite data from IRIS -LISS and GIS databases to identify areas susceptible to forest fire in India. The factors affecting forest fire were merged based on their weight and degree of importance. Land cover type, slope and distance from residential areas and roads were the most important contributing parameters in this model. The fire risk zones were very low, low, moderate, high, and very high. In this forest division, $55.75 \%$ of the area falls under "high" and "very high" fire risk zones, $27.26 \%$ of the area falls under a "moderate" fire risk zone, and 16.99\% of the area falls under "low" and "very low" fire risk zones.

Erten, Kurgun et al. [63] also investigated hazardous parameters of forest fires based on the Dong model using satellite data and GIS in the context of the Gallipoli Peninsula in Turkey. In this study, the TM imagery was classified before and after the forest fire event. Other morphological information was extracted from a topographical map of 1: 25000 using 
GIS work frame. Then, the information was ranked based on its weight and importance in fire distribution. The results showed that there is a high likelihood of forest fire event in the areas with dry vegetation, high slope, southern slope direction and near roads or residential areas.

Sowmya and Somashekar [3] prepared a map of forest fire risk areas for the Bhadra Wildlife Sanctuary in India, using an appropriate weighting using the analytic hierarchy process (AHP). The variables used included vegetation, slope, distance from the road and distance from residential areas. The temporal satellite from 1989 to 2006 was analysed to map the burnt areas. The results showed a high accuracy compared to a previous fire inventory map, which can be used for future fire prevention policies.

Ghobadi, Gholizadeh et al. [64] mapped the areas at risk of forest fire using GIS in the Golestan province of Iran. To do this, the factors that contributed to the risk of fire, such as topography, slope, slope direction, meteorological data and vegetation cover, were examined. Fire hazard areas were determined by assigning special weights to each class of all layers on a basis of sensitivity to fire. Finally, the risk of forest fire from very low to very high level was presented. The increment in the applied indices and their change according to the environmental conditions were studied in different regions.

Eskandari, Ghadikolaei et al. [65] evaluated the efficiency of the Dong model to predict areas at a high risk of forest fire in northern Iran. After deriving all the effective factors, they were classified according to the Dong model in GIS. Finally, the map of the potential fire-risk regions was developed from the weighted variables via the Dong model. The results showed that $51 \%$ of the actual fires were located in high-risk zones, which indicated the moderate efficiency and accuracy of the Dong model for predicting future forest fires.

Thakur and Singh [66] assessed the forest fire hazard in the Dehradun District in India using analytical hierarchy process (AHP) and GIS. To do this, factors such as vegetation humidity, slope, direction, height, distance from the road and residential areas were considered. These factors were weighted based on their impact. The results showed that $98 \%$ of the fires in the past were in areas with a high or moderate risk of fire. The results also showed that most of the fires in the study area were from natural causes and were not due to human factors.

Eskandari and Miesel [67] evaluated the efficiency of the Dong model to determine the fire risk of the forests in the Mazandaran province in Iran. All the digital contributing layers were classified according to the Dong model. The factors used included type and density of vegetation, slope, slope direction, height, and distance from roads, residential areas and agricultural land. Using all of the maps in the GIS and ranking each factor using the model, the forest fire risk map was constructed with areas classified from very low to very high for fire risk potential. The results showed that approximately $40 \%$ of the previous fires were located in areas with a high risk of fire. Then, the layers were ranked based on their importance, and a new improved model was introduced. Following the construction of fire risk maps using the three methods, the map of the actual fires was overlaid to validate the used methods. The results showed that approximately $80 \%$ of previous fires were in zones with a high risk of forest fire, which indicated the significant improvement of the revised model for the study area. 
Kanga, Kumar et al. [26] identified forest fire by overlaying layers that were weighed in different classes in tropical forest of India. They used LISS 3 and ASTER DEM imagery as well as thematic layers such as elevation, slope, aspect, mean annual temperature, humidity, wind speed, accessibility to settlement and fuel map of the region. The model estimates the loss of forest resources due to unexpected wild fires. They also extracted the forest fire risk map, forest density map and LULC layer.

Sakellariou, Tampekis et al. [68] studied the influence of both natural and anthropogenic factors on the forest fire phenomena as well as determining the fire risk levels based on the local features of an island in the northern part of Greece. To do this, fuel inventory (tree type and density) data, digital orthophoto and DEM were processed. Contributing factors were considered, including local characteristics of topography (slope, aspects), fuel, and the influence of human factors. They used a multi-criteria approach exploiting GIS capabilities to weight the contributing factors. The result showed a high accuracy hence it can be considered to be a valuable tool for a significant number of cases and more specifically when there is a shortage of fire probability.

\subsubsection{Application of ensemble models}

Vakalis, Sarimveis et al. [69] presented a GIS-based operating system for managing fire hazards using a combination of a fuzzy inference system (FIS) and neural network (NN) based on available data from historical fires. The purpose of developing this model was to use it as a decision support system in order to allocate the fire-fighting resources to the optimal place. In this research, according to the experts' opinion, a number of input variables were selected, including flammability of vegetation, vegetation density, slope of the region, air temperature and wind speed.

Dong, Li-min et al. [70] developed a hybrid approach with RS and GIS to map fire risk areas in the Baihe forestry basin of China. Topographic parameters (i.e. slope, aspect and elevation) were obtained from a digital elevation model; while biomass and land use maps were extracted from the Landsat satellite ETM + image. In addition, areas at risk of fire were identified from the weighted classes of all the layers. The results showed the model achieved high accuracy in terms of forest fire risk analysis, particularly in areas of high fire risk.

Adab, Kanniah et al. [71] modelled the fire risk in Golestan forests using GIS and RS techniques. The structural fire indicator, the fire hazard indicator and a new index called the hybrid fire indicator were used to determine the fire hazard in this study. Slope, aspect, height, distance from roads and residential areas, and vegetation humidity were selected as the effective factors in the occurrence of the forest fire. These layers were combined in the GIS by assigning weights to their classes based on fire sensitivity. The MODIS hotspot data was used to validate the indices. The evaluation of the indices by the ROC curves showed an accuracy of $76.6 \%$ for the hybrid fire indicator which is higher than the other two indicators. Based on their results, $57.5 \%$ of the studied area was in a high danger zone, $33 \%$ in a moderate danger zone and $9.5 \%$ in a low danger zone in terms of forest fire.

Bui, Bui et al. [72] developed a new artificial intelligent approach called Particle Swarm Optimized Neural Fuzzy (PSO-NF) for the spatial modelling of tropical forest fire susceptibility. Ten ignition factors, namely, slope, aspect, altitude, land use, NDVI, distance to residence area, distance to road, temperature, precipitation, and wind speed were collected 
to construct a GIS database. The results showed that the proposed model performs well, both on the training dataset $(\mathrm{AUC}=0.932)$ and the validation dataset $(\mathrm{AUC}=0.916)$. The model achieved high performance on both the training and validation datasets indicating that these parameters were successfully selected by the PSO algorithm, therefore the algorithm is an efficient metaheuristic algorithm that should be used to optimize the parameters for the neural fuzzy model.

Pourghasemi, Beheshtirad et al. [89] assessed forest fire susceptibility using modified analytical hierarchy process (M-AHP) and Mamdani fuzzy logic (MFL) models in Golestan Province, Iran. Seven contributing parameters, namely, altitude, aspect, slope, temperature, wind, land use, and NDVI, were derived in GIS framework. The results showed that the accuracy rates for M-AHP and MFL are $77.7 \%$ and $88.2 \%$, respectively. fire susceptibility maps can be used for fire suppression resource planning, allocation works and early warning programs.

Eskandari and Miesel [67] modelled forest fire risk in the city of Neka in Iran using the fuzzy AHP method in the form of multi-criteria decision analysis. The factors used included four main criteria and 17 sub-criteria. The main criteria were topographic, biological, climate, and human standards. Using their model, first, the map of the main criteria (from the weighting of the sub criteria of each criterion) was prepared and then the final map of the forest fire risk of the region was created by the integration of the weight of the maps of the four main criteria. The results showed that high-risk fire areas were consistent with the risk maps prepared by the past-burnt areas, which indicates that the model was valid and reliable.

Sachdeva, Bhatia et al. [13] developed wildfire susceptibility maps using a proposed EOGBDT model in the context of the northern part of India. They compared their results with other ML and data-driven models such as NN, RF, SVM, PSO-SVM. The datasets that were used for this research were ASTER DEM imagery, inventory data, and consortium for spatial information (CGIAR-CSI), global weather data, soil data and Landsat 8 satellite image, as well as 18 ignition factors of elevation, slope, aspect, plan curvature, topographic position index, topographic water index, normalized difference vegetation index, soil texture, temperature, rainfall, aridity index, potential evapotranspiration, relative humidity, wind speed, land cover and distance from roads, rivers and habitations. The proposed model, EOGBDT, achieved an overall accuracy of $95.5 \%$. The generated susceptibility map with susceptible defined areas would augment the government initiatives of wildlife protection and management, allowing them to bring immediate emphasis on those regions of higher volatility and wildfire risks.

\subsection{Detection of forest fire using RS}

The use of remote satellite observations to detect forest fire has significantly accelerated over the last two decades as the temporal, spectral, and spatial resolution of the sensors have been continually improved [73]. Furthermore, new satellite image processing algorithms have been proposed to maximize the accuracy of forest fire detection [74]. The Advanced Very High Resolution Radiometer (AVHRR) was one of the first satellite sensors to provide a remote dataset from affected forest areas. It is based on measuring temperature variations of the forest surface using multiple spectral bands of thermal infrared and short-wave infrared. Numerous algorithms have been developed to detect fire spots in the forest from AVHRR images [75, 76]. Later on, using other satellite images such as ATSR or MODIS which can be processed for fire detection, several robust algorithms have also been suggested [77, 78]. 
Crofts (1998) presented a management plan for forest fires in Pukaskwa, Canada, using a GIS from satellite imagery. This management plan was designed for a pine forest that was burned in 1998. To this end, the park level was divided into three zones of fire management, and solutions for preventing forest fires and fire management in each zone were presented. The results of this study showed that the updated satellite information is a strong tool especially on a large scale that can be used for fire management in Canadian National Parks.

In a study conducted by Giri and Shrestha [79], forest fire factors and resources were surveyed in 1998 in Thailand, using Landsat TM satellite imagery. The burned areas were identified and detected by classifying the Landsat image. To assess the effects of fire, several samples were taken using a GPS in both burned and unpolluted areas. The results showed a precision classification of $88.3 \%$ for burned areas where most of the fires were unintentional. At the end, the researchers created a GIS database to have effective fire indicators for mapping the forest risk areas and forest fire simulation.

Paz, Carmel et al. [80] assessed fire risk based on forest change detection for the Carmel region of Israel from 2007 to 2009 . The forest border was detected using infrared satellite data (ASTER-NASA) and then fire risk maps were prepared based on variations of climatic factors, vegetation cover, fuel type and human factors. The results showed that most of the forest areas that burned in 2009 were in the high-risk areas of the fire risk map. This indicates that the proposed model has a high degree of reliability for predicting future fires.

Jaafari, Gholami et al. [81] presented a simple model for the preparation of risk maps and fire alarms in forest areas using Landsat ETM +. Using this model and satellite imagery and the digital elevation model (DEM), high-risk fire areas were detected. For this purpose, three factors of gradient, slope and NDVI contributing to forest fire were formulated and applied from the satellite imagery. Consequently, the areas of high risk were identified.

Sifakis, Iossifidis et al. [73] used multiple temporal SEVIRI sensors from Meteosat Second Generation (MSG) geostationary satellite, which have 12 spectral bands, to detect the forest fire in Greece in 2007. These imageries were processed to perform as near real-time detection and tracking system. An active Fire Monitoring (FIR) image processing algorithm for fire detection and monitoring was applied and assessed. Their results showed the MSG-SEVIRI dataset effectively detected $82 \%$ of the fire events.

\subsection{GIS-based forest-fire-induced Natech risk management}

GIS and remote sensing techniques are becoming progressively essential in hazard and risk administration actions not only for modelling and monitoring natural hazards but also for industrial and Natech disasters. Natural disasters like forest fires, which can be caused by either internal or external triggers, might threaten an industrial complex and its distribution network $[82,83]$. As such, natural and human-made hazards, which can lead to significant industrial accidents, should be tackled by comprehensive GIS-based Natech risk management. In contrast with natural disasters, industrial and man-made disasters are more "spatially predictable" because they might occur solely in areas that are used for industrial purposes [84].

There have been several cases [35] where forest fire has expanded to industrial sectors and caused Natechs. Basically, the consequences of a forest-fire-induced Natech can be divided into three categories: fire, explosion and the release of toxic substances which can delay an 
emergency response during or immediately after the disaster. To reduce the negative impact of forest fire on industrial plants, it is suggested that new construction development in forest fire high-risk zones be avoided, as highlighted by precise geospatial methodologies like ML and ensemble models. In addition, integrated land management and vegetation management strategies are urgently required. Prevention, mitigation, and resilience strategies which consider both environmental and structural protections against forest fire should be strongly considered by industrial plants which already operate in high risk areas. These strategies include upgrading facilities using fire-resistant materials, removing and clearing the surrounding fuel, replacing flammable vegetation with fire-resistant plants in the surrounding area, increasing public education and preparedness, and allocating emergency firefighting centers within proper distance from potential Natech locations [85].

At present, the detection, monitoring and mapping of Natechs is not well-developed among the authorities. There are a few agencies (e.g. Joint Research Centre of European Commission) which are designing remote sensing platforms for the mapping and temporal monitoring of Natech events [86]. Satellite images with a wide range of spectral wavelengths that can recognise and monitor fires in conjunction with geospatial datasets and frameworks can play a significant role in the containment and restraint of Natechs. Satellite images like DLR (Deutschen Zentrum für Luft- und Raumfahrt), ESA (European Space Agency), NASA (National Aeronautics and Space Administration), NOAA (National Oceanic and Atmospheric Administration), and EUMETSAT (European Organisation for the Exploitation of Meteorological Satellites) along with machine learning, and statistical GIS models can detect and simulate forest fires to mitigate the effects of these disasters [87]. Additionally, drones can be extremely useful during the emergency phase of forest-fire-induced events which rescue teams cannot reach. They can be equipped with surveillance instruments such as toxic detector sensors, visible and infrared sensors and laser scanning systems [88]. The captured information can be transferred in real-time to geospatial frameworks to accurately simulate and predict fire behaviour. Technically speaking, the spatial and temporal development of Natechs is the foremost aim that should be achieved for rapid and effective geospatial data acquisition, processing and mapping.

\section{Research Challenges and Future Directions}

The increasing trend of forest fires demands a prediction and control strategy. Considering the various factors that affect forest fires, modelling the risk of occurrence of fire regarding all the contributing factors to fire occurrence is an accurate way to predict forest fire. Since most of the influencing factors have a spatial dimension, GIS can play an important role in such modelling. In the context of forest fire management using GIS, various studies have been conducted in the forests of the world. A review of the research on forest fire probability in different parts of the world shows that a GIS can develop, manage and predict forest fire activities. Therefore, creating a GIS database is essential for mapping fire hazard, risk and susceptibility. In many cases, the type of vegetation, slope, geographic location, distance from permanent roads and rivers, topography and land use are the most effective contributing factors in fire occurrence. In addition, Landsat (with TM, ETM +, OLI sensors), IRS (with LISS III, IV sensors) AVHRR and MODIS satellite imagery has been widely used to detect forest fires. 
The overall results of these studies indicate that there is a high likelihood of forest fire occurrence in a warm climate with dry vegetation and soil, inclined areas, wind speed, south face aspect and near road and residential areas. The predicted forest fire map that shows high and low susceptible areas should be compared with a historical fire inventory to evaluate the accuracy of the applied method. In recent studies, the integration of hierarchical analysis and fuzzy sets have been used to model the risk of fire occurrence. In some newer studies, the integration of the fuzzy inference system and the neural network, artificial intelligence and SVM have been used to predict the probable regimes to fire. In addition, in more advanced methods, logistic regression and decision tree algorithms are used to provide fire hazard modelling. Multi-criteria analysis is a topic that has been proposed in recent research and organizing metrics in the form of a model of spatial data using GIS.

Regarding validation assessment, ensemble models, ML, MCDM and data-driven methods have shown higher accuracy, respectively. In this study, we made a general comparison between the discussed methods and we highlighted their pros and cons in forest fire application (Table 1 ).

Table 1: The advantages and disadvantages of different geospatial models for forest fire.

\begin{tabular}{|c|c|c|}
\hline Method & Advantage & Disadvantage \\
\hline $\begin{array}{l}\text { Data- } \\
\text { driven }\end{array}$ & $\begin{array}{l}\text { - Simple and reliable way to assess potential forest } \\
\text { fire risk } \\
\text { - Little historical data required on fires to map } \\
\text { forest fire zones } \\
\text { - Easy to apply } \\
\text { - Quantitative results }\end{array}$ & $\begin{array}{l}\text { - In practical applications, the } \\
\text { variables of conceptual } \\
\text { model must be adjusted to fit } \\
\text { into the actual situation } \\
\text { - Not as accurate as ML }\end{array}$ \\
\hline ML & $\begin{array}{l}\text { - Less number of inventories } \\
\text { - Precise results } \\
\text { - High accuracy } \\
\text { - Inter-relation of parameters determined } \\
\text { - Ability of fusion with other methods } \\
\text { - Quantitative results }\end{array}$ & $\begin{array}{l}\text { - Needs to use a detailed and } \\
\text { accurate inventory layer } \\
\text { - Not popular in forest fire } \\
\text { modelling so far }\end{array}$ \\
\hline Ensemble & $\begin{array}{l}\text { - High performance on both training and } \\
\text { validation of very-high accuracy } \\
\text { - Inter-relation of parameters determined } \\
\text { - All aspects of application considered } \\
\text { - Quantitative results }\end{array}$ & $\begin{array}{l}\text { - Difficult to implement } \\
\text { - No commercial software yet } \\
\text { - Need optimization } \\
\text { algorithms to achieve the best } \\
\text { result } \\
\text { - Need a detailed and accurate } \\
\text { inventory layer }\end{array}$ \\
\hline MCDM & $\begin{array}{l}\text { - Hierarchical structures to represent a problem } \\
\text { - Alternatives priorities determined based on } \\
\text { experts' judgment } \\
\text { - Easy to update } \\
\text { - Well-known and well-tested }\end{array}$ & $\begin{array}{l}\text { - Subjective to different human } \\
\text { opinions } \\
\text { - Can only apply on } \\
\text { categorized parameters } \\
\text { - Qualitative results }\end{array}$ \\
\hline
\end{tabular}

Since forest fire is one of the main environmental disasters in the world, the pattern recognition of wild large fires and fire susceptibility mapping are the best measures to mitigate the effects of fire. However, it is important to note that each of the fire risk modelling 
and evaluation methods presented in this study has its own advantages and disadvantages. Because the condition of forests is different all over the world, the proposed model should be calibrated with local parameters at the first step to implement this for forest ecosystems in a particular region. To use any model for mapping the potential hazard of forest fire in forests, it is necessary to calibrate these models regarding the local forests' conditions. In other words, we need to consider all environmental factors affecting the occurrence of such forest fires (e.g. soil depth, soil moisture, climatic variables). Due to the high precision of geospatial information methods for forest fire modelling (i.e. risk, hazard, susceptibility, detection and prediction), it is recommended to use an industrial party for funding. In recent studies, FR, LR and DT, AHP algorithms have been used to model forest fire susceptibility, hazard and risk. In more advanced methods, the integration of methods was discussed such as the FIS with the NN, ANN with SVM and optimizing neural fuzzy with particle swarm optimized called on to predict the future fires.

\section{Conclusion and future works}

Forest fire maps can help natural hazard managers to identify high potential fire danger areas. These models can be implemented in other areas to address the forest fire problem by altering the risk factors and their weights. The generated probability, susceptibility, hazard and risk maps augment the government instrumentalities of forest wildlife protection and management, enabling an immediate emphasis to be placed on vulnerable, volatile areas which are at risk of wildfire. Considering the various spatial factors affecting forest fires, modelling the incidence of fire with respect to the contributing parameters is a popular methodology to predict fire occurrence in forests. According to current reviews, it can be concluded that statistical and data-driven approaches are the most frequently used methods while ensemble and machine learning approaches achieve higher accuracy.

In contrast to natural disasters, industrial and man-made disasters are more predictable because they tend to occur solely in areas that are devoted to industrial purposes. Satellites images in conjunction with the geospatial datasets and methods can detect, monitor, model and predict Natech disasters. In relation to future investments in Natech, we believe that drone-based photogrammetry can push the boundaries of risk assessment and management due to its significant ability to acquire data during a fire disaster.

Public awareness via educational campaigns and media announcements, which should be conducted frequently, can highlight the importance of preventative measures. Also, further work should be conducted to expand the current scientific and technological achievements in the design of a sustainable approach to forest fire management. Future research needs to focus on more accurate sensors and satellite imagery to detect fire events much more precisely and include a wider range of management objectives. Additionally, using other real-time fire data is necessary to evaluate the accuracy of a fire risk map.

\section{References}

[1] Podur J, Martell DL, Knight K. Statistical quality control analysis of forest fire activity in Canada. Canadian Journal of Forest Research. 2002;32:195-205.

[2] Liu W, Wang S, Zhou Y, Wang L, Zhang S. Analysis of forest potential fire environment based on GIS and RS. Geoinformatics, 2010 18th International Conference on: Ieee; 2010. p. 1-6. 
[3] Sowmya S, Somashekar R. Application of remote sensing and geographical information system in mapping forest fire risk zone at Bhadra wildlife sanctuary, India. Journal of Environmental Biology. 2010;31:969.

[4] Mangeas M, André J, Gomez C, Despinoy M, Wattelez G, Touraivane T. A spatially explicit integrative model for estimating the risk of wildfire impacts in New-Caledonia. International Journal of Parallel, Emergent and Distributed Systems. 2018:1-16.

[5] Lampin-Maillet C, Mantzavelas A, Galiana L, Jappiot M, Long M, Herrero G, et al. Wildland urban interfaces, fire behaviour and vulnerability: characterization, mapping and assessment. European Forest Institute; 2010.

[6] Herawati H, Santoso H. Tropical forest susceptibility to and risk of fire under changing climate: A review of fire nature, policy and institutions in Indonesia. Forest Policy and Economics. 2011;13:22733.

[7] Buxton M, Haynes R, Mercer D, Butt A. Vulnerability to bushfire risk at Melbourne's urban fringe: the failure of regulatory land use planning. Geographical Research. 2011;49:1-12.

[8] Ager AA, Vaillant NM, Finney MA. Integrating fire behavior models and geospatial analysis for wildland fire risk assessment and fuel management planning. Journal of Combustion. 2011;2011.

[9] Krausmann E, Baranzini D. Natech risk reduction in the European Union. Journal of Risk Research. 2012;15:1027-47.

[10] Alexandridis A, Vakalis D, Siettos CI, Bafas GV. A cellular automata model for forest fire spread prediction: The case of the wildfire that swept through Spetses Island in 1990. Applied Mathematics and Computation. 2008;204:191-201.

[11] Pacheco AP, Claro J, Fernandes PM, de Neufville R, Oliveira TM, Borges JG, et al. Cohesive fire management within an uncertain environment: a review of risk handling and decision support systems. Forest Ecology and Management. 2015;347:1-17.

[12] Mutlu M, Popescu SC, Zhao K. Sensitivity analysis of fire behavior modeling with LIDARderived surface fuel maps. Forest Ecology and Management. 2008;256:289-94.

[13] Sachdeva S, Bhatia T, Verma A. GIS-based evolutionary optimized Gradient Boosted Decision Trees for forest fire susceptibility mapping. Natural Hazards. 2018;92:1399-418.

[14] Morgan P, Keane RE, Dillon GK, Jain TB, Hudak AT, Karau EC, et al. Challenges of assessing fire and burn severity using field measures, remote sensing and modelling. International Journal of Wildland Fire. 2014;23:1045-60.

[15] Keane RE, Menakis JP, Hessburg PF, Reynolds KM, Dickinson JD. Evaluating wildfire hazard and risk for fire management applications. Making Transparent Environmental Management Decisions: Springer; 2014. p. 111-33.

[16] Fairbrother A, Turnley JG. Predicting risks of uncharacteristic wildfires: application of the risk assessment process. Forest Ecology and Management. 2005;211:28-35.

[17] Robinne F-N, Burns J, Kant P, Flannigan M, Kleine M, de Groot B, et al. Global Fire Challenges in a Warming World. IUFRO; 2018.

[18] Minas JP, Hearne JW, Handmer JW. A review of operations research methods applicable to wildfire management. International Journal of Wildland Fire. 2012;21:189-96.

[19] Sakellariou S. Spatiotemporal analysis of forest fire risk models: a case study for a greek island 2018.

[20] Zhang Y, Lim S, Sharples JJ. Modelling spatial patterns of wildfire occurrence in south-eastern Australia. Geomatics, Natural Hazards and Risk. 2016;7:1800-15.

[21] Calkin DE, Cohen JD, Finney MA, Thompson MP. How risk management can prevent future wildfire disasters in the wildland-urban interface. Proceedings of the National Academy of Sciences. 2014;111:746-51.

[22] You W, Lin L, Wu L, Ji Z, Yu Ja, Zhu J, et al. Geographical information system-based forest fire risk assessment integrating national forest inventory data and analysis of its spatiotemporal variability. Ecological Indicators. 2017;77:176-84. 
[23] Alkhatib AA. A review on forest fire detection techniques. International Journal of Distributed Sensor Networks. 2014;10:597368.

[24] Union E. Forest Fires in Europe, Middle East and North Africa 2017. 2018.

[25] Duff TJ, Tolhurst KG. Operational wildfire suppression modelling: a review evaluating development, state of the art and future directions. International Journal of Wildland Fire. 2015;24:735-48.

[26] Kanga S, Kumar S, Singh, SK. Climate induced variation in forest fire using Remote Sensing and GIS in Bilaspur District of Himachal Pradesh. International Journal of Engineering and Computer Science. 2017;6.

[27] Lee B, Alexander M, Hawkes B, Lynham T, Stocks B, Englefield P. Information systems in support of wildland fire management decision making in Canada. Computers and Electronics in Agriculture. 2002;37:185-98.

[28] Chuvieco E, Congalton RG. Application of remote sensing and geographic information systems to forest fire hazard mapping. Remote sensing of Environment. 1989;29:147-59.

[29] Modugno S, Balzter H, Cole B, Borrelli P. Mapping regional patterns of large forest fires in Wildland-Urban Interface areas in Europe. Journal of environmental management. 2016;172:112-26.

[30] Yassemi S, Dragićević S, Schmidt M. Design and implementation of an integrated GIS-based cellular automata model to characterize forest fire behaviour. ecological modelling. 2008;210:71-84.

[31] Haas JR, Calkin DE, Thompson MP. Wildfire risk transmission in the Colorado Front Range, USA. Risk analysis. 2015;35:226-40.

[32] Pyne SJ. Fire in America: a cultural history of wildland and rural fire: University of Washington Press; 2017.

[33] Sakellariou S, Tampekis S, Samara F, Sfougaris A, Christopoulou O. Review of state-of-the-art decision support systems (DSSs) for prevention and suppression of forest fires. Journal of Forestry Research. 2017;28:1107-17.

[34] Mhawej M, Faour G, Adjizian-Gerard J. Wildfire likelihood's elements: A literature review. Challenges. 2015;6:282-93.

[35] Sorensen C. The Fort McMurray wildfire has hit the oil sands hard. 2016.

[36] Heymes F, Aprin L, Forestier S, Slangen P, Jarry JB, François H, et al. Impact of a distant wildland fire on an LPG tank. Fire safety journal. 2013;61:100-7.

[37] Khakzad N, Dadashzadeh M, Reniers G. Quantitative assessment of wildfire risk in oil facilities. Journal of environmental management. 2018;223:433-43.

[38] Khakzad N. Impact of wildfires on Canada's oil sands facilities. Natural Hazards and Earth System Sciences. 2018;18:3153-66.

[39] Scarponi GE, Landucci G, Heymes F, Cozzani V. Experimental and numerical study of the behavior of LPG tanks exposed to wildland fires. Process Safety and Environmental Protection. 2018;114:251-70.

[40] Khakzad N. Modeling wildfire spread in wildland-industrial interfaces using dynamic Bayesian network. Reliability Engineering \& System Safety. 2019;189:165-76.

[41] Moher D, Liberati A, Tetzlaff J, Altman DG, The PG. Preferred Reporting Items for Systematic Reviews and Meta-Analyses: The PRISMA Statement. PLOS Medicine. 2009;6:e1000097.

[42] Moher D, Liberati A, Tetzlaff J, Altman DG. Preferred reporting items for systematic reviews and meta-analyses: the PRISMA statement. Annals of internal medicine. 2009;151:264-9.

[43] Rollins MG, Keane RE, Parsons RA. Mapping fuels and fire regimes using remote sensing, ecosystem simulation, and gradient modeling. Ecological Applications. 2004;14:75-95.

[44] Pradhan B, Awang MA. Application of remote sensing and gis for forest fire susceptibility mapping using likelihood ratio model. Proceedings of Map Malaysia. 2007.

[45] Lozano FJ, Suárez-Seoane S, Kelly M, Luis E. A multi-scale approach for modeling fire occurrence probability using satellite data and classification trees: A case study in a mountainous Mediterranean region. Remote Sensing of Environment. 2008;112:708-19. 
[46] Martínez J, Vega-Garcia C, Chuvieco E. Human-caused wildfire risk rating for prevention planning in Spain. Journal of environmental management. 2009;90:1241-52.

[47] Perera AH, Cui W. Emulating natural disturbances as a forest management goal: Lessons from fire regime simulations. Forest Ecology and Management. 2010;259:1328-37.

[48] Keane RE, Drury SA, Karau EC, Hessburg PF, Reynolds KM. A method for mapping fire hazard and risk across multiple scales and its application in fire management. Ecological Modelling. 2010;221:2-18.

[49] Chuvieco E, Aguado I, Yebra M, Nieto H, Salas J, Martín MP, et al. Development of a framework for fire risk assessment using remote sensing and geographic information system technologies. Ecological Modelling. 2010;221:46-58.

[50] Zumbrunnen T, Pezzatti GB, Menéndez P, Bugmann H, Bürgi M, Conedera M. Weather and human impacts on forest fires: 100 years of fire history in two climatic regions of Switzerland. Forest Ecology and Management. 2011;261:2188-99.

[51] Jurdao S, Chuvieco E, Arevalillo JM. Modelling fire ignition probability from satellite estimates of live fuel moisture content. Fire Ecology. 2012;8.

[52] Román MV, Azqueta D, Rodrígues M. Methodological approach to assess the socio-economic vulnerability to wildfires in Spain. Forest Ecology and Management. 2013;294:158-65.

[53] Gerdzheva AA. A comparative analysis of different wildfire risk assessment models (a case study for Smolyan District Bulgaria. European Journal of Geography. 2014;5:22-36.

[54] Eskandari S, Chuvieco E. Fire danger assessment in Iran based on geospatial information. International Journal of Applied Earth Observation and Geoinformation. 2015;42:57-64.

[55] Chuvieco E, Aguado I, Jurdao S, Pettinari ML, Yebra M, Salas J, et al. Integrating geospatial information into fire risk assessment. International Journal of Wildland Fire. 2014;23:606-19.

[56] Hong H, Naghibi SA, Dashtpagerdi MM, Pourghasemi HR, Chen W. A comparative assessment between linear and quadratic discriminant analyses (LDA-QDA) with frequency ratio and weights-ofevidence models for forest fire susceptibility mapping in China. Arabian Journal of Geosciences.

2017;10:167.

[57] Vadrevu KP, Eaturu A, Badarinath K. Fire risk evaluation using multicriteria analysis - a case study. Environmental monitoring and assessment. 2010;166:223-39.

[58] Sakr GE, Elhajj IH, Mitri G, Wejinya UC. Artificial intelligence for forest fire prediction.

Advanced Intelligent Mechatronics (AIM), 2010 IEEE/ASME International Conference on: IEEE; 2010.

p. 1311-6.

[59] Sitanggang I, Yaakob R, Mustapha N, Ainuddin A. Predictive models for hotspots occurrence using decision tree algorithms and logistic regression. Journal of applied sciences. 2013;13:252-61.

[60] Almeida R. Forest fire risk areas and definition of the prevention priority planning actions using

GIS. EUROPEAN CONFERENCE ON GEOGRAPHICAL INFORMATION SYSTEMS-EGIS1994.

[61] Akpinar E, Usul N. GIS in forest fires. City and Regional Planner Project Cordinator in INTA SpaceTurk, Turkey, 11p. 2003.

[62] Jaiswal RK, Mukherjee S, Raju KD, Saxena R. Forest fire risk zone mapping from satellite imagery and GIS. International Journal of Applied Earth Observation and Geoinformation. 2002;4:1-10.

[63] Erten E, Kurgun V, Musaoglu N. Forest fire risk zone mapping from satellite imagery and GIS: a case study. XXth Congress of the International Society for Photogrammetry and Remote Sensing, Istanbul, Turkey2004. p. 222-30.

[64] Ghobadi GJ, Gholizadeh B, Dashliburun OM. Forest fire risk zone mapping from geographic information system in Northern Forests of Iran (Case study, Golestan province). International Journal of Agriculture and Crop Sciences. 2012;4:818-24.

[65] Eskandari S, Ghadikolaei JO, Jalilvand H, Saradjian MR. Detection of fire high-risk areas in northern forests of Iran using Dong model. World Applied Sciences Journal. 2013;27:770-3.

[66] Thakur AK, Singh D. Forest Fire Risk Zonation Using Geospatial Techniques and Analytic Hierarchy Process in Dehradun District, Uttarakhand, India. Universal Journal of Environmental Research \& Technology. 2014;4. 
[67] Eskandari S, Miesel JR. Comparison of the fuzzy AHP method, the spatial correlation method, and the Dong model to predict the fire high-risk areas in Hyrcanian forests of Iran. Geomatics,

Natural Hazards and Risk. 2017;8:933-49.

[68] Sakellariou S, Tampekis S, Samara F, Flannigan M, Jaeger D, Christopoulou O, et al.

Determination of fire risk to assist fire management for insular areas: the case of a small Greek island. Journal of Forestry Research. 2018:1-13.

[69] Vakalis D, Sarimveis H, Kiranoudis C, Alexandridis A, Bafas G. A GIS based operational system for wildland fire crisis management I. Mathematical modelling and simulation. Applied Mathematical Modelling. 2004;28:389-410.

[70] Dong X, Li-min D, Guo-fan S, Lei T, Hui W. Forest fire risk zone mapping from satellite images and GIS for Baihe Forestry Bureau, Jilin, China. Journal of forestry research. 2005;16:169-74.

[71] Adab H, Kanniah KD, Solaimani K. Modeling forest fire risk in the northeast of Iran using remote sensing and GIS techniques. Natural hazards. 2013;65:1723-43.

[72] Bui DT, Bui Q-T, Nguyen Q-P, Pradhan B, Nampak H, Trinh PT. A hybrid artificial intelligence approach using GIS-based neural-fuzzy inference system and particle swarm optimization for forest fire susceptibility modeling at a tropical area. Agricultural and forest meteorology. 2017;233:32-44.

[73] Sifakis NI, Iossifidis C, Kontoes C, Keramitsoglou I. Wildfire Detection and Tracking over Greece Using MSG-SEVIRI Satellite Data. Remote sensing. 2011;3:524-38.

[74] Lentile LB, Holden ZA, Smith AM, Falkowski MJ, Hudak AT, Morgan P, et al. Remote sensing techniques to assess active fire characteristics and post-fire effects. International Journal of Wildland Fire. 2006;15:319-45.

[75] Cuomo V, Lasaponara R, Tramutoli V. Evaluation of a new satellite-based method for forest fire detection. International Journal of Remote Sensing. 2001;22:1799-826.

[76] Kaufman YJ, Setzer A, Justice C, Tucker C, Pereira M, Fung I. Remote sensing of biomass burning in the tropics. Fire in the tropical biota: Springer; 1990. p. 371-99.

[77] Wooster M, Zhukov B, Oertel D. Fire radiative energy for quantitative study of biomass burning: derivation from the BIRD experimental satellite and comparison to MODIS fire products. Remote Sensing of Environment. 2003;86:83-107.

[78] Justice C, Giglio L, Korontzi S, Owens J, Morisette J, Roy D, et al. The MODIS fire products. Remote Sensing of Environment. 2002;83:244-62.

[79] Giri C, Shrestha S. Forest fire mapping in Huay Kha Khaeng wildlife sanctuary, Thailand. 2000.

[80] Paz S, Carmel Y, Jahshan F, Shoshany M. Post-fire analysis of pre-fire mapping of fire-risk: A recent case study from Mt. Carmel (Israel). Forest Ecology and Management. 2011;262:1184-8.

[81] Jaafari A, Gholami DM, Zenner EK. A Bayesian modeling of wildfire probability in the Zagros Mountains, Iran. Ecological informatics. 2017;39:32-44.

[82] Clerc A. The environment impacts of natural and technological (NA-TECH) disasters. World Conference of Natural Disaster Reduction Topical Session No 6: UN. Environment Program (UNEP); 1994.

[83] Cruz AM, Steinberg LJ, Vetere Arellano A, Nordvik J-P, Pisano F. State of the art in Natech risk management. Report EUR. 2004;21292.

[84] Marzo E, Busini V, Rota R. Definition of a short-cut methodology for assessing the vulnerability of a territory in natural-technological risk estimation. Reliability Engineering \& System Safety.

2015;134:92-7.

[85] FireSmart. Canadian Guidebook for the Oil and Gas Industry. Alberta, Canada2012.

[86] Girgin S, Krausmann E. RAPID-N: Rapid Natech risk assessment and mapping framework. Journal of Loss Prevention in the Process Industries. 2013;26:949-60.

[87] Showalter PS, Ramspott M, Mortan D, Prosperie L, Walter L. The use of remote sensing in detecting and analyzing natural hazards and disasters, 1972-1998: A partially annotated bibliography: James and Marilyn Lovell Center for Environmental Geography and Hazards Research, Department of Geography, Southwest Texas State University; 1999. 
[88] Di Franco S, Salvatori R. Current situation and needs in man-made and Natech risks management using Earth Observation techniques. Remote Sensing Applications: Society and Environment. 2015;1:72-84.

[89] Pourghasemi HR, Beheshtirad M, Pradhan B. A comparative assessment of prediction capabilities of modified analytical hierarchy process (M-AHP) and Mamdani fuzzy logic models using NetcadGIS for forest fire susceptibility mapping. Geomatics, Natural Hazards and Risk. 2016;7:861-85. 